\title{
Memory properties in cloud--resolving simulations of the diurnal cycle of deep convection
}

\author{
Article \\ Published Version \\ Creative Commons: Attribution 4.0 (CC-BY) \\ Open Access
}

Daleu, C. L., Plant, R. S., Woolnough, S. J., Stirling, A. J. and Harvey, N. J. (2020) Memory properties in cloud--resolving simulations of the diurnal cycle of deep convection. Journal of Advances in Modeling Earth Systems, 12 (8). e2019MS001897. ISSN 1942-2466 doi: https://doi.org/10.1029/2019MS001897 Available at https://centaur.reading.ac.uk/91673/

It is advisable to refer to the publisher's version if you intend to cite from the work. See Guidance on citing.

To link to this article DOI: http://dx.doi.org/10.1029/2019MS001897

Publisher: American Geophysical Union

All outputs in CentAUR are protected by Intellectual Property Rights law, including copyright law. Copyright and IPR is retained by the creators or other copyright holders. Terms and conditions for use of this material are defined in the End User Agreement. 


\section{CentAUR}

Central Archive at the University of Reading

Reading's research outputs online 


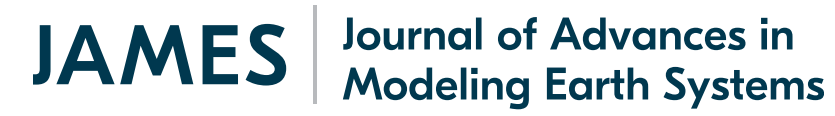

\section{RESEARCH ARTICLE 10.1029/2019MS001897 \\ Memory Properties in Cloud-Resolving Simulations of the Diurnal Cycle of Deep Convection}

Key Points:

- The effetcs of previous convection in modifying current development of convection is strongest at gray-zone scales of 4 to $10 \mathrm{~km}$

- Rain cores become more intense when thermodynamic fluctuations from previous day influence the evolution of convection on the next day

- Convective memory attributed to thermodynamic variability resulting from previous diurnal cycle mostly resides in the lower troposphere

Correspondence to:

C. L. Daleu,

c.daleu@reading.ac.uk

Citation:

Daleu, C. L., Plant, R. S., Woolnough, S. J., Stirling, A. J., \& Harvey, N. J. (2020) Memory properties in cloud-resolving simulations of the diurnal cycle of deep convection. Journal of Advances in Modeling Earth Systems, 12, e2019MS001897. https://doi.org/ 10.1029/2019MS001897

Received 16 SEP 2019 Accepted 5 JUL 2020 Accepted article online 8 JUL 2020

(C)2020. The Authors.

This is an open access article under the terms of the Creative Commons Attribution License, which permits use, distribution and reproduction in any medium, provided the original work is properly cited.

\author{
C. L. Daleu ${ }^{1}$ (D), R. S. Plant ${ }^{1}$ iD, S. J. Woolnough ${ }^{2}$ (D, A. J. Stirling ${ }^{3}$, and N. J. Harvey ${ }^{1}$ \\ ${ }^{1}$ Department of Meteorology, University of Reading, Reading, UK, ${ }^{2}$ National Centre for Atmospheric Science, Department \\ of Meteorology, University of Reading, Reading, UK, ${ }^{3}$ Met Office, Exeter, UK
}

\begin{abstract}
A series of high-resolution three-dimensional simulations of the diurnal cycle of deep convection over land are performed using the new Met Office NERC cloud-resolving model. This study features scattered convection. A memory function is defined to identify the effects of previous convection in modifying current convection. It is based on the probability of finding rain at time $t_{0}$ and at an earlier time $t_{0}-\Delta t$ compared to the expected probability given no memory. The memory is examined as a function of the lag time $\Delta t$. It is strongest at gray-zone scales of $4-10 \mathrm{~km}$, there is a change of behavior for spatial scales between 10 and $15 \mathrm{~km}$, and it is reduced substantially for spatial scales larger than $25 \mathrm{~km}$. At gray-zone scales, there is a first phase of the memory function which represents the persistence of convection and it is maintained for about an hour. There is a second phase which represents the suppression of convection in regions which were raining 1 to $3 \mathrm{hr}$ previously, and subsequently a third phase which represents a secondary enhancement of precipitation. The second and third phases of the memory function develop earlier for weaker forcing. When thermodynamic fluctuations resulting from the previous day are allowed to influence the development of convection on the next day, there are fewer rainfall events with relatively large sizes, which are more intense, and thus decay and recover more slowly, in comparison to the simulations where feedback from previous days is removed. Further sensitivity experiments reveal that convective memory attributed to these thermodynamic fluctuations resides in the lower troposphere.
\end{abstract}

Plain Language Summary Identifying the effects of previous convection in modifying the subsequent development of convection is important for correctly capturing the large-scale effects of moist convection (convective parameterization) in numerical models used for weather forecasts and climate prediction. We evaluate these memory effects from idealized cloud-resolving model simulations of the diurnal cycle of scattered convection. We find that the main convective systems persist for about an hour. Later, convection is suppressed in those regions which were raining 1 to $3 \mathrm{hr}$ previously, and later still there is a secondary enhancement of convection in the regions that were previously suppressed. These memory effects are sensitive to the size of the region over which they are evaluated: they are small for length scales coarser than $50 \mathrm{~km}$ but become increasingly important at scales of $10 \mathrm{~km}$ or less. At these finer scales they are inconsistent with the diagnostic assumptions made in many current convective parameterization schemes. We also investigated the effects of the previous day's convective activity on that of the next day, in particular through the effects on spatial variability of temperature and moisture in the lower troposphere. If the variability associated with the previous day is artificially removed, then the convective systems become numerous but less intense. They are found to be smaller and to decay more rapidly, with a more rapid recovery of the atmosphere in their vicinity.

\section{Introduction}

Tropical convection provides the most important source of energy for the global-scale atmospheric flow. Over land, it is observed to undergo strong diurnal variation in intensity, with rainfall peaking in the late afternoon or evening (e.g., Lin et al., 2000; Yang \& Slingo, 2001). This diurnal variation of convection plays a key role in the global climate system since the resulting clouds and precipitation strongly modulate the atmospheric radiative budget, water budget, and surface fluxes. The diurnal cycle is strongly coupled to physical processes parameterized in general circulation models (GCMs). These include, boundary layer heating, surface heat exchange, cloud-radiation interactions, often the convection itself. Therefore, it is necessary to predict correctly the phasing of convection with solar radiation in order to get an accurate radiation budget, and the ability of GCMs to capture the correct phasing is an important test of model parameterizations. 
Despite the improvement in the parameterization of model physical processes made over the past decade, current state-of-art GCMs still have difficulty to capture the broad pattern of the diurnal variation of convection, in terms of intensity and phase (e.g., Bechtold et al., 2004; Betts \& Jakob, 2002; Hohenegger \& Stevens, 2013; Lee et al., 2008; Yang \& Slingo, 2001). In particular, GCMs that capture the intensity of the diurnal cycle tend to produce an onset of precipitation early in the day compared to observations (e.g., Bechtold et al., 2004; Betts \& Jakob, 2002; Lin et al., 2000; Yang \& Slingo, 2001). The superparameterization approach (e.g., Grabowski, 2001; M. F. Khairoutdinov \& Randall, 2001; M. Khairoutdinov et al., 2005) has been demonstrated to improve the simulated diurnal cycle of precipitation. However, the integrations are computationally expensive. Some recent studies have improved the representation of convection using different approaches and produced some improvements in the diurnal cycle representation. Approaches include modifications to the closure (Bechtold et al., 2014) or entrainment (Stratton \& Stirling, 2012), a representation of the control of convection by boundary layer thermals and cold pools (Rio et al., 2013), and a unification of shallow and deep convection including both cold pool and mesoscale representations (Park et al., 2019).

The difficulties of GCMs in predicting the diurnal cycle suggest that parameterizations respond too quickly to surface forcing. Colin et al. (2019) provide a good description of the main issues in this regard. Convection schemes generally focus on relatively large spatial scales and make the "quasi-equilibrium" assumption (Arakawa, 2004; Arakawa \& Schubert, 1974; Yano \& Plant, 2012), that convection balances the large-scale forcing. Most convection schemes also involve a separate "triggering" formulation and diagnose whether a triggering variable satisfies particular conditions before determining the closure variable that governs how convection responds to the large-scale forcing. The key point stressed by Colin et al. (2019) is that both the triggering and closure are usually treated as diagnostic (sections $5 \mathrm{~b}$ and $5 \mathrm{c}$ in Arakawa, 2004) so that the parameterized convective effects depend only on state variables at the grid scale and at the same time. However, these diagnostic assumptions become increasingly questionable as progress is being made toward running GCMs with higher-resolution and shorter time steps.

Following Davies et al. (2009) and Colin et al. (2019), we refer to "memory" as being the information that needs to be retained about previous convection in order to determine the characteristics of current convection. Various authors have attempted to introduce elements of memory into convection parameterizations (e.g., Chen \& Bougeault, 1992; Grandpeix \& Lafore, 2010; Park, 2014; Randall \& Pan, 1993; Rio et al., 2019; Yano \& Plant, 2012). However, as Colin et al. (2019) recognized, there is little consistency within these and other approaches in terms of the variables that are chosen to be prognostic or, relatedly, the assumed physical origins for the memory mechanism. This study seeks to bring new insights on the relationship between convection and its own history.

There are several well-documented cases of idealized diurnal cycles. For instance, in the European Cloud Systems (EUROCS) Project case study, Guichard et al. (2004) presented a series of cloud-resolving model (CRM) and single-column model (SCM) results from multiday simulations of the diurnally varying convection over one of the Atmospheric Radiation Measurement (ARM) sites centered over the Southern Great Plains (SGP), USA, during summer 1997. Other intercomparison studies that have been helpful in this respect include the CRMs and SCMs simulations of the diurnal cycle that were performed within the Global Energy and Water-cycle Experiment (GEWEX) cloud system study (GCSS) Working Group 4 Case 3 framework (e.g., Xie et al., 2002; Xu et al., 2002).

Stirling and Petch (2004) investigated the impact of spatial variability generated via feedback processes from previous convection on current development of convection. They demonstrated that the onset of precipitation and total rain amount can change significantly if internally generated thermodynamic variability from a day of deep convection is included in the initial thermodynamic conditions. This suggests that the presence of spatial variability in the initial thermodynamic conditions preconditions the atmosphere, influences the subsequent development of convection, and thus provides a mechanism for memory. Further investigations have provided more evidence that convective memory is carried by thermodynamic variability (Colin et al., 2019; Davies et al., 2013). Other possible sources identified for memory include free tropospheric moisture variations (e.g., Dudhia et al., 1987; Redelsperger et al., 2002), cold pools and gust fronts due to evaporation of precipitation (e.g., Mapes \& Houze, 1992; Tompkins, 2001), drylines (e.g., Bluestein \& Parker, 1993), and horizontal convective rolls (e.g., Weckwerth et al., 1996). 
Davies et al. (2013) focused on memory for different periods of imposed forcing, while (Colin et al., 2019) focused on the effects of organization on memory. Here, we investigate disorganized convection with an imposed diurnal forcing time scale and focus on evaluating how memory can be characterized for different length scales and its dependence on the chosen forcing strength. Results from the new Met Office NERC cloud model (MONC; N. Brown et al., 2015) simulations of the diurnal cycle of deep convection over land will be presented. The simulated case is an idealization of the EUROCS diurnal-cycle deep-convection case study (Guichard et al., 2004). Specifications of the EUROCS case study along with the results from several CRMs and SCMs are described in Bechtold et al. (2004). Another major focus of this study will be on assessing the impacts that thermodynamic variability generated at night after decaying deep convection has on the next day's convective development. We will determine the time scale and length scale within which convective memory is effective.

\section{Model Description and Simulation Setup}

\subsection{The New MONC}

The CRM used in this study is the MONC (N. Brown et al., 2015), which is a rewrite of the original Met Office Large-Eddy Model (LEM). The original Met Office LEM (as described by Petch \& Gray, 2001; Shutts \& Gray, 1994) has been successfully exploited for modeling convective and cloud-related processes in a variety of regimes (e.g., A. R. Brown et al., 2002; Brown, 1999; Clark et al., 2005; Connolly et al., 2006, 2013; Marsham et al., 2006; Young et al., 2017). It has been rewritten to include a new solver that enables simulations to be performed with relatively large domain sizes without having to compromise on model resolution. Other improvements include bug fixes and code optimizations. The reader is referred to N. Brown et al. (2015) for further details.

Cloud processes are simulated using the newly developed user-configurable Cloud AeroSol Interactive Microphysics (CASIM) scheme. CASIM is a multimoment scheme that represents five hydrometeor species; cloud water, rain, ice, snow, and graupel. In this study, CASIM represents each of those species using prognostic variables for both the mixing ratios and number concentrations. Autoconversion and accretion are represented using the scheme developed by M. Khairoutdinov and Kogan (2000), and the sedimentation of the five hydrometeor species is also represented. Condensation and evaporation of cloud droplets are represented using a saturation adjustment scheme, while rain evaporation is represented as in the LEM (Gray et al., 2001). CASIM has recently been used to study the role of droplet sedimentation in the evolution of low-level clouds in MONC (e.g., Dearden et al., 2018). It has also been configured for multimode aerosols to study aerosol-cloud interactions in the UK Met Office Unified Model (e.g., Grosvenor et al., 2017; Miltenberger et al., 2018; Stevens et al., 2018).

\subsection{Simulation Settings}

The horizontal domain size is $512 \times 512$ grid points and the horizontal resolution is $200 \mathrm{~m}$. The vertical grid consists of 99 levels, on a stretched grid with finer resolution closer to the surface. The vertical grid spacing is stretched from $35 \mathrm{~m}$ near the surface to $250 \mathrm{~m}$ in the upper troposphere $(12 \mathrm{~km})$, and increasing to $450 \mathrm{~m}$ near the model top, which is at $20 \mathrm{~km}$. The lateral boundary conditions are biperiodic for all prognostic variables. The top and bottom of the domain are rigid lids, and a Newtonian damping layer is used aloft (from 15 to $20 \mathrm{~km}$ ). A 3-D Smagorinsky scheme is used to calculate subgrid turbulent eddy fluxes. The Coriolis parameter is set to zero, and the horizontal mean winds are relaxed toward zero with a relaxation time scale of $1 \mathrm{hr}$.

For the purposes of this study, we focus on the atmospheric variability controlling memory, and so to separate that out from that resulting from the surface properties, we choose not to couple the model to an interactive land surface. For the control simulation the surface specification closely follows the EUROCS diurnal-cycle deep-convection case study (Guichard et al., 2004). The model is forced with prescribed horizontally homogeneous surface forcing which vary sinusoidally during the day (0-12 hr) and are set to zero at night (12-24 hr). The peaks in sensible and latent heat fluxes are reached at $6 \mathrm{hr}$ and they are 130 and 400 $\mathrm{W} \mathrm{m}^{-2}$, respectively.

The model is forced with a net atmospheric radiation term that represents the combined effects of shortwave and longwave radiation. It is horizontally homogeneous and noninteractive and will be referred to as 

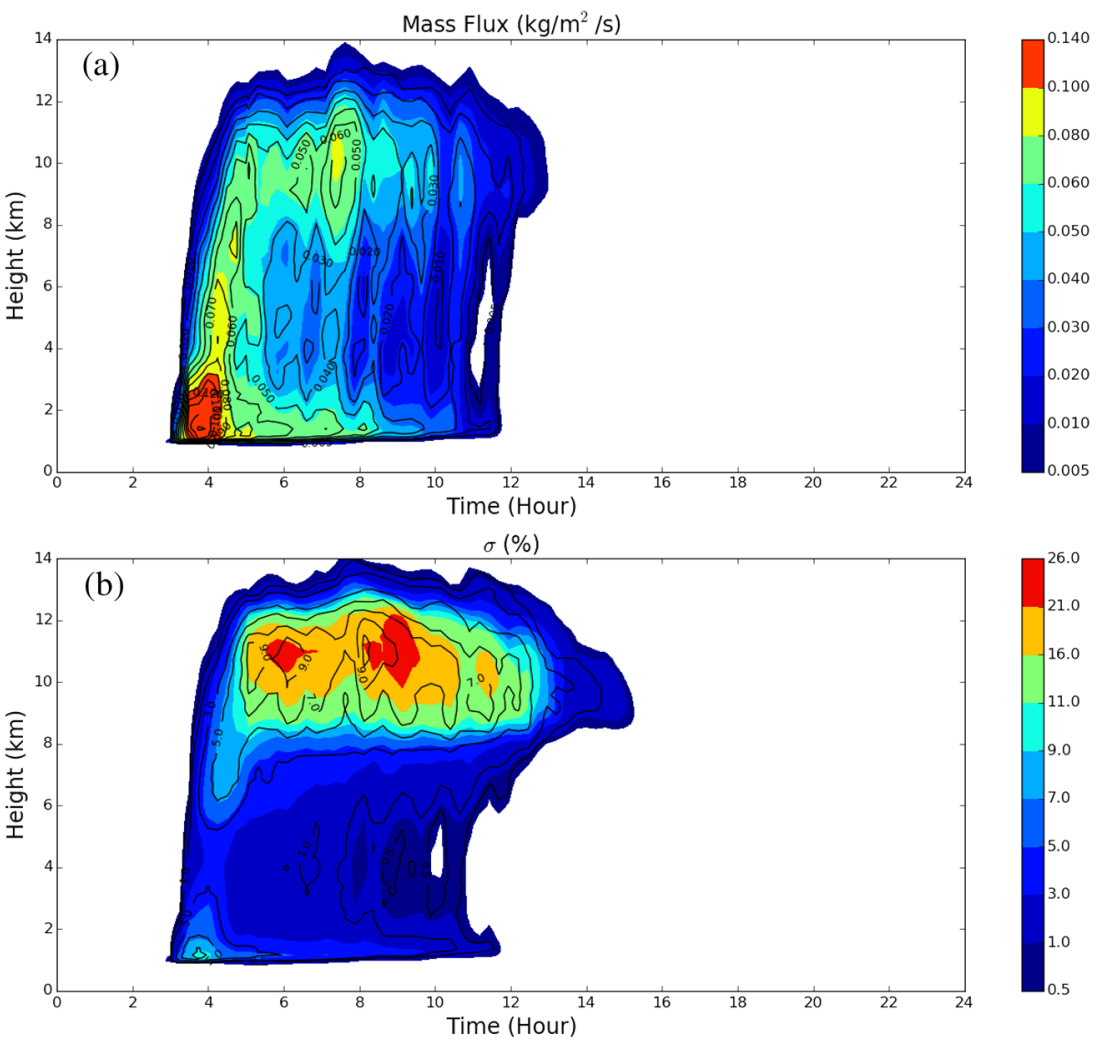

Figure 1. Time-height cross sections of (a) mass flux and (b) cloud fraction. Results are shown for the components attributed to (colors) all cloudy updrafts ("ACu”) and (solid contours) buoyant cloudy updrafts ("BCu”). The mass fluxes are given per unit area. The fractional area attributed to "BCu" (or "ACu") is calculated at each horizontal level as the sum of cloudy updrafts (or buoyant cloudy updrafts) grid points normalized by the total number of grid points. The results are obtained on the second diurnal cycle of the control simulation. For each panel the contour intervals are the same as the color bar spacing.

radiative cooling. The cooling is applied to potential temperature. It has a constant value of $-1.75 \mathrm{~K}^{\text {day }}{ }^{-1}$ from the surface to $12 \mathrm{~km}$ and decreasing linearly in height to reach $0 \mathrm{~K} \mathrm{day}^{-1}$ at $15 \mathrm{~km}$. During the night (12-24 hr), an additional cooling of $-3.1 \mathrm{~K} \mathrm{day}^{-1}$ is applied at the surface decreasing linearly to zero at 1 $\mathrm{km}$. These idealized cooling profiles (day and night) are designed to balance the prescribed time-varying surface fluxes over a 24-hr period (complete forcing cycle), so that the simulations remain energetically closed in terms of the moist static energy budget. The additional cooling rate applied at night approximately matches the mean radiative cooling in the lowest $1 \mathrm{~km}$ at night in an equivalent simulation of the diurnal cycle of convection using the idealized setup of the UK Met Office Unified Model with the same settings but with interactive radiation (not shown). In this study, it is applied in order to produce a stable boundary layer at dawn, and thus to delay the triggering and onset of precipitation on the next diurnal cycle.

To investigate the sensitivity to the strength of forcing, we also performed weakly and strongly forced simulations. The Bowen ratio is the same as that in the control simulation, but the values of sensible and latent heat fluxes and the values of radiative cooling rates are reduced by $50 \%$ in the weakly forced simulation and increased by $50 \%$ in the strongly forced simulation. To ensure statistically significant results, all three simulations are run for 10 successive diurnal cycles.

\section{Evaluation of Convective Properties Over Time-Varying Surface Forcing}

\subsection{Evaluation Over One Complete Forcing Cycle}

Analysis of the control simulation in terms of convective stability and boundary layer height has shown that the model is able to reproduce a diurnal cycle of these parameters (not shown). Figure 1 shows the 

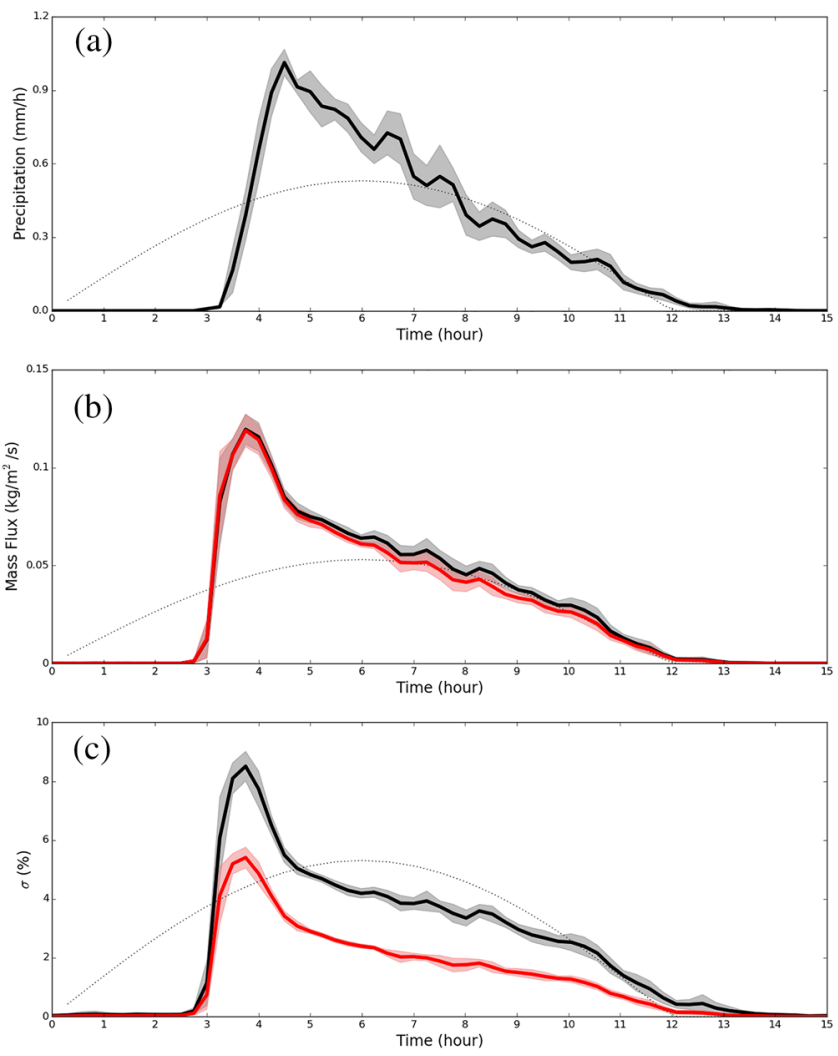

Figure 2. Composite time series of (a) precipitation, (b) cloud base mass flux, and (c) cloud fraction at cloud base. The mass flux and cloud fraction are shown for (black curves) "ACu" and (red curves) "BCu." The mass fluxes are given per unit area. The shaded areas indicate the cycle-to-cycle fluctuations relative to the ensemble mean value (standard deviation). Time series of surface forcing (sum of sensible and latent heat fluxes) scaled by (a) $10^{3}$, (b) $10^{4}$, and (c) $10^{2}$ are shown for reference. time-height cross sections of the domain average mass flux ( $\rho w)$ and cloud fraction $(\sigma)$ for the control simulation. Here, we show the mass flux and cloud fraction of two conditional sampled diagnostics: all cloudy updrafts ("ACu"; shading) and buoyant cloudy updrafts or cloud cores ("BCu"; contours). All cloudy updrafts are defined by grid points with mixing ratio of liquid cloud $\left(q_{l}\right)$ or ice $\left(q_{i}\right)$ greater than $10^{-5} \mathrm{~kg} \mathrm{~kg}^{-1}$ and positive vertical velocity $(w>0)$, while cloud cores are defined as cloudy updraft points which are also positively buoyant with respect to the layer mean $\left(\theta_{v}^{\prime}>0\right.$ $\mathrm{K})$. Here, the fractional area attributed to "BCu" (or " $\mathrm{ACu}$ ") is calculated at each horizontal level as the sum of cloudy updrafts (or buoyant cloudy updrafts) grid points normalized by the total number of grid points. Results in Figure 1 are shown for the second diurnal cycle of the control simulation but are similar for the nine diurnal cycles used in our analysis.

The initial response of convection, termed "triggering" corresponds to the development of shallow convection at the top of the boundary layer. In the control simulation the triggering starts at $\sim 2.75 \mathrm{hr}$ and convection develops rapidly through the troposphere. Deep cloud tops reach levels as high as $12 \mathrm{~km}$ at $4 \mathrm{hr}$ (1.25 hr after triggering), then emerge further and reach the maximum level of about $14 \mathrm{~km}$ at $7.75 \mathrm{hr}$. The cloud base rises slowly through the day, consistent with the warming and deepening of the subcloud layer.

Cloud fractions show a bimodal distribution. The first mode centered at about $1.5 \mathrm{~km}$ is due to shallow convection, while the second, broadest mode which extends from 6 to $14 \mathrm{~km}$ results from intermediate and deep convection. These profiles of cloud fractions broadly agree with those obtained in previous studies of this nature (e.g., Guichard et al., 2004; Xie et al., 2002; Xu et al., 2002).

In the lower and middle troposphere convection starts to weaken gradually shortly after $4 \mathrm{hr}$. As a result, liquid clouds forming below the freezing level located at about $5 \mathrm{~km}$ decay accordingly and vanish completely as convection stops. In the upper troposphere the largest cloud fractions occur shortly after $5 \mathrm{hr}$. As the lower and middle tropospheric clouds decay, the upper tropospheric clouds dominate the skies. These clouds decay more slowly and vanish completely at $15 \mathrm{hr}$, that is about $2 \mathrm{hr}$ after the mass flux has decayed in the upper troposphere. Between 15 and $24 \mathrm{hr}$ the column is free from convection and cloud.

The free tropospheric cooling rate applied in the control simulation is weaker than the value of about -2 $\mathrm{K} \mathrm{day}^{-1}$ applied in previous studies of the diurnal cycle of convection with similar values of surface forcing (e.g., Stirling \& Petch, 2004; Xu et al., 2002). In preliminary simulations with $-2 \mathrm{~K}$ day $^{-1}$ cooling rate, we found that condensation (upper-level anvils and/or low-level clouds) and sometimes convection were generated between 15 and $24 \mathrm{hr}$ and before triggering on the next diurnal cycle (not shown). As the air becomes colder at night, condensation can occur, and the latent heat released can trigger convective activity. The stronger the cooling rate in the free troposphere, the quicker the air cools below its dew point value and in the control simulation a cooling rate smaller or equal to $-1.75 \mathrm{~K} \mathrm{day}^{-1}$ is required to ensure that no regions of saturation are formed between 15 and $24 \mathrm{hr}$ and before triggering on the next diurnal cycle. However, as we will discuss in section 3.2.2, choosing a different radiative cooling profile does not significantly change the memory function that illustrates the dependence of convection on its own history.

We analyzed the time-height cross sections of the spatially averaged mass flux and cloud fraction for the weakly and strongly forced simulations (not shown). The weakly forced simulation is free from convection and clouds between 15 and $24 \mathrm{hr}$ and the triggering is at $3.25 \mathrm{hr}$. In the strongly forced simulation the triggering is at $2.5 \mathrm{hr}$ but clouds occur from $20 \mathrm{hr}$ to a couple of hours after the start of surface forcing on the next forcing cycle as a result of condensation from radiative cooling overnight. Analysis reveals that these clouds 

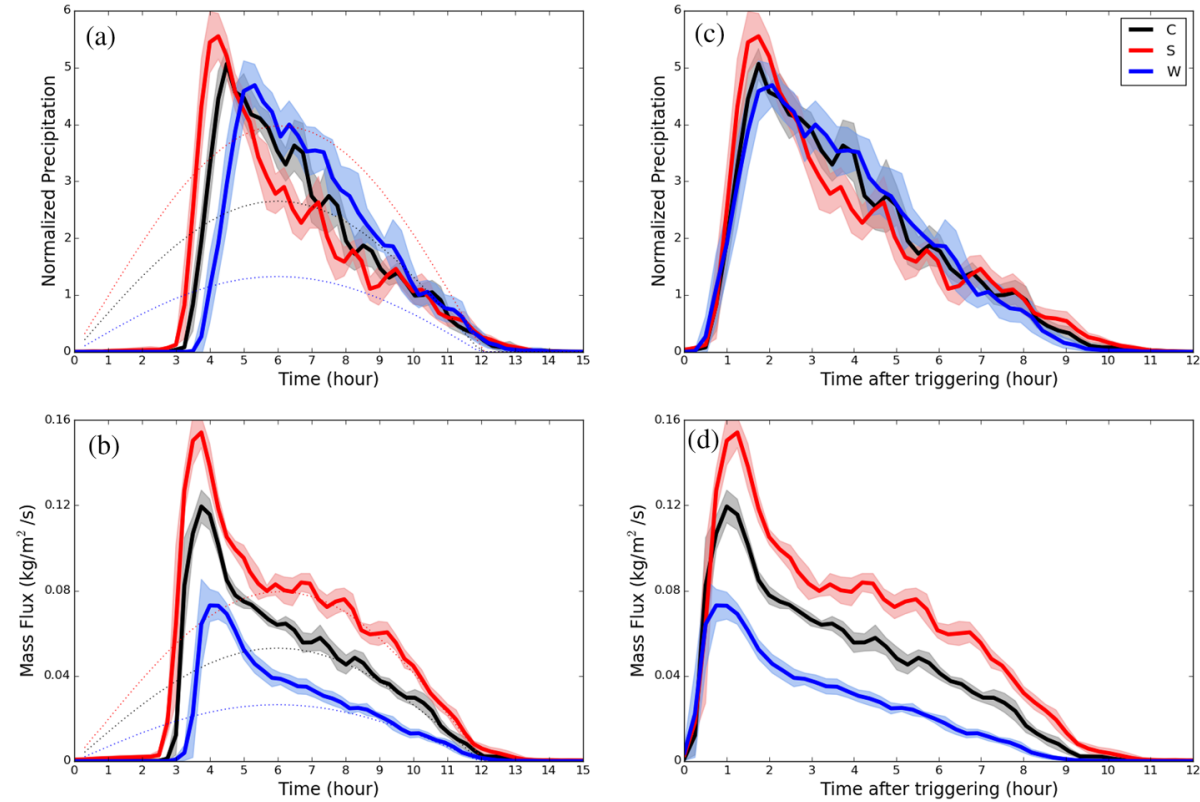

Figure 3. Composite time series of (a) normalized precipitation and (b) cloud base mass flux for "ACu." The normalized precipitation is defined as the instantaneous precipitation rates normalized by the domain mean daily mean precipitation rate. Results are shown for the (black) control simulation and for the (blue) weakly and (red) strongly forced simulations. The mass fluxes are given per unit area. The shaded areas indicate the cycle-to-cycle fluctuations relative to the ensemble mean value (standard deviation). Time series of surface forcing (sum of sensible latent heat fluxes) scaled by (a) $10^{3}$ and (b) $10^{4}$ are shown for reference. The results on panels (c) and (d) are the same as those on panels (a) and (b), but the time axis is shifted such that time equals 0 corresponds to the time of triggering in all three simulations.

are generated within two thin layers; at the top of the boundary layer (associated with light precipitation) and around the freezing level. However, in all three simulations the triggering corresponds to a rapid intensification of convection and the rates of growth of cloud tops are very similar, with cloud tops exceeding $10 \mathrm{~km} 1 \mathrm{hr}$ after triggering. Analysis of the horizontal cross sections of clouds also reveals that convection is disorganized in all three simulations.

\subsection{Evaluation Over Multiple Forcing Cycles}

We now discuss the characteristics of the ensemble over multiple forcing cycles. For each of the three simulations, the last nine cycles are considered to form an ensemble of simulations of the diurnal cycle differentiated by the initial conditions. The end of the diurnal cycle $i-1$ provides starting conditions for the cycle $i$. The start of each of the nine cycles is considered to be Time 0 and ensemble mean results are obtained.

Figure 2 shows the composite time series of surface precipitation rates, mass flux, and cloud fraction attributed to all cloudy updrafts and buoyant cloudy updrafts at cloud base. Here, the cloud base height is defined as the lowest point in the domain where $q_{l}>10^{-5} \mathrm{~kg} \mathrm{~kg}^{-1}$. Results are shown for the nine control simulations and the shaded areas represent the standard deviation from the ensemble mean of each quantity, which is used to quantify the cycle-to-cycle fluctuations relative to the ensemble mean.

The time of triggering is defined as the time just before the sharp increase of cloud base mass flux occurs. It is at $\sim 2.75 \mathrm{hr}$ and the rapid intensification of convection with deep convective cloud top emerging rapidly into the upper troposphere and sharp increase in surface precipitation rates are common to each cycle. The peak in precipitation is at $4.5 \mathrm{hr}$ (1.75 hr after triggering). Cloud fraction and mass flux at cloud base reach their maximum values at $3.75 \mathrm{hr}$, then adjust rapidly to much smaller values. From $4.5 \mathrm{hr}$, surface precipitation, cloud base mass flux, and cloud fraction continue to decrease until shortly after the surface forcing is switched off.

The details of the evolution of the convection (e.g., timing and values of precipitation, mass flux, and cloud fraction) vary from one forcing cycle to the other, but overall, the composite time series of precipitation shows a greater variability than those of mass flux and cloud fraction. Between 3 and $11 \mathrm{hr}$, the fractional 
area covered by cloud cores represents about $60 \%$ of that of all cloudy updrafts. However, the values of mass flux are very close for the two definitions, suggesting that cloud cores are the dominant source of mass flux.

Figures $3 \mathrm{a}$ and $3 \mathrm{~b}$ show the composite time series of the normalized precipitation and the cloud base mass flux, respectively, for different forcing strengths. The normalized precipitation is defined as the instantaneous precipitation rates divided by the domain mean daily mean precipitation rate. The domain mean and daily mean precipitation rate is about $0.2 \mathrm{~mm} \mathrm{hr}^{-1}$ in the control simulation, and it is reduced (increased) by $50 \%$ in the weakly (strongly) forced simulation, consistent with the strength of forcing (section 2.2).

As discussed in section 3.1 the triggering is delayed with decreasing strength of forcing. The time of triggering is at $2.5 \mathrm{hr}$ in the strongly forced simulation, $2.75 \mathrm{hr}$ in the control simulation, and $3.25 \mathrm{hr}$ in the weakly forced simulation. Figures $3 \mathrm{c}$ and $3 \mathrm{~d}$ show the same results as in Figures $3 \mathrm{a}$ and $3 \mathrm{~b}$ but the time axis is shifted such that time equals 0 corresponds to the time of triggering in all three simulations. Convection is more active (in terms of mass flux) as the strength of forcing is increased. However, the normalized precipitation is seen to evolve at very similar rates, reaching its peak at 1.75 (in the control and strongly forced simulations) or 2 (in the weakly forced simulation) hours after triggering.

3.2.1. Rainfall Distribution

In this section, we examine the evolution of the rainfall population using instantaneous 2-D surface precipitation fields output every $15 \mathrm{~min}$. By adopting a precipitation threshold of $0.1 \mathrm{~mm} \mathrm{hr}^{-1}$ in all three simulations (that is $50 \%$ of the domain mean daily mean surface precipitation rate in the control simulation), any grid point with precipitation greater than that threshold is masked as rainy. A simple algorithm is then applied to classify the resulting 2-D masked field into clusters or rainfall events. We will refer to these rainfall events as rain cores and in the rest of the text, rain cores and rainfall events will be used interchangeably. Starting from any rainy grid point a cluster $i$ is formed by connecting rainy points in the $x$ and $y$ directions. The area of the cluster $i$ is then computed as $A_{i}=n_{i} \Delta x \Delta y$ where $n_{i}$ is the number of rainy grid points that belong to that cluster and $\Delta x$ and $\Delta y$ are the horizontal grid spacings in the $x$ and $y$ directions, respectively. The number of rain cores, $N$, is the total number of clusters, and the mean rain core area, $\bar{A}$ is

$$
\bar{A}=\frac{1}{N} \sum_{i=1}^{N} A_{i}
$$

Figure 4a presents the composite of rain core area probability distribution functions (PDFs). Results are the average of PDFs between [0.25-0.75], [1-1.25], [1.5-1.75], [2-2.5], [2.75-6.5], and [6.75-9.5] hr after triggering in the control simulation. The majority of rainfall events produced within the first hour after triggering are less than $4 \mathrm{~km}^{2}$. As time progresses, larger rainfall events are produced, resulting in a broadening of rain core area distribution. The distributions between Hours 2.5-9.5 are very similar. They are relatively broad, with many small rainfall events $\left(A_{i}<10 \mathrm{~km}^{2}\right)$ as well as some large ones. Thus, a simple mean rain core radius may not be sufficient to assess the evolution of the rainfall populations; a rain core radius standard deviation, $\sigma_{R}$ is also useful.

By assuming that rainfall population consists mostly of events with more or less round shapes, the mean rain core radius, $R$, is estimated as

$$
R=\sqrt{\frac{\bar{A}}{\pi}} .
$$

The composite time series of the mean rain core radius, standard deviation of rain core radii, and number of rainfall events are shown in Figures $4 \mathrm{~b}-4 \mathrm{~d}$, respectively. The time axis is shifted such that time equals 0 corresponds to the time of triggering in all three simulations.

The first rainfall events develop $15 \mathrm{~min}$ after triggering in the control and weakly forced simulations, with mean radii of about 0.7 and $0.4 \mathrm{~km}$, respectively. In the strongly forced simulation light precipitation commences before triggering (for the reason given in section 3.1), and rainfall events generated at triggering are larger, with a mean radius of about $1 \mathrm{~km}$. After triggering, the evolution of the average radius can be divided into two stages. The growing stage characterized by a gradual growth of rain core radius extends from 0.75 to 2.75 (in the strongly forced simulation), 3 (in the control simulation), and $4 \mathrm{hr}$ (in the weakly 

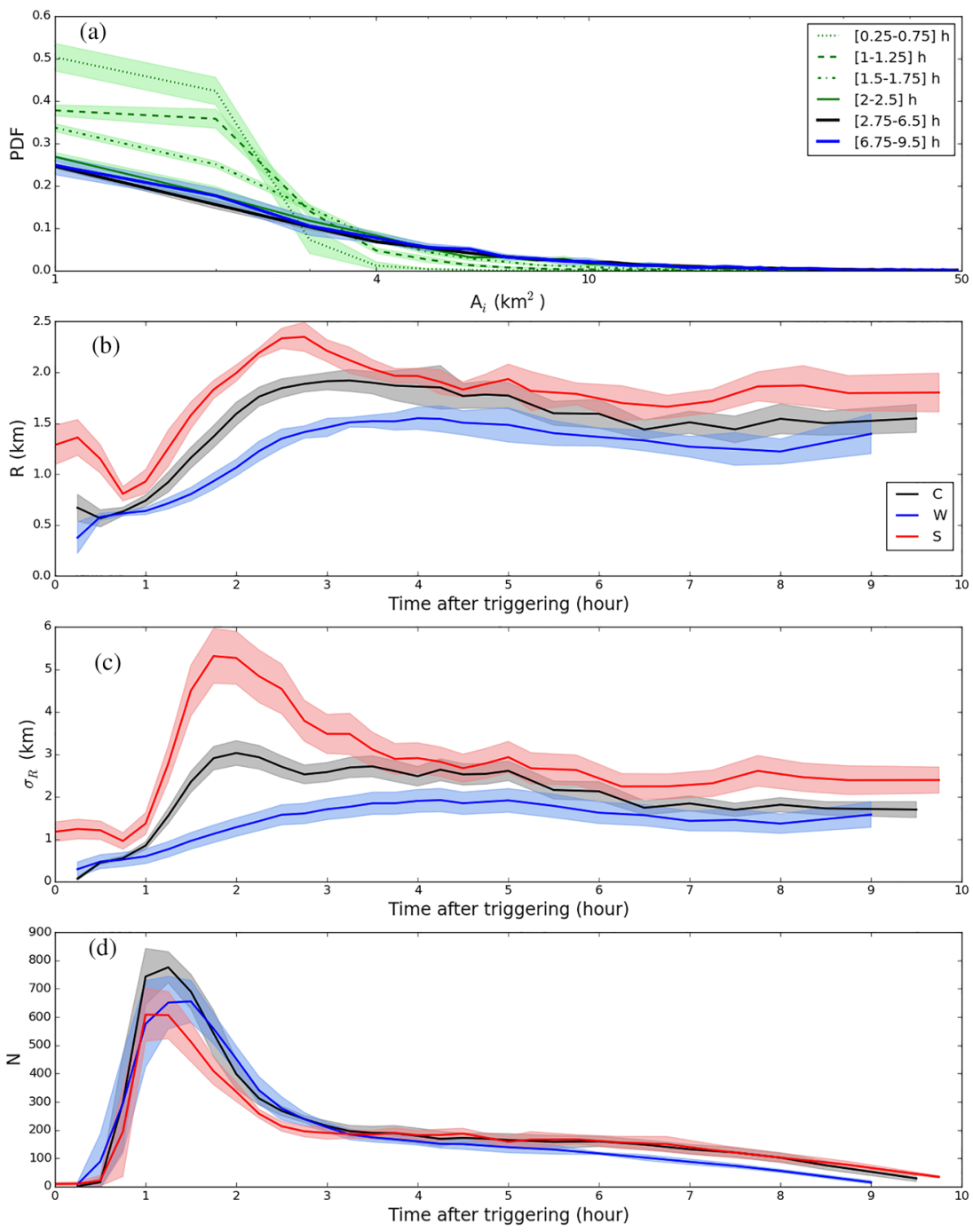

Figure 4. (a) Composite of PDFs of rain core area. Results are the average of PDFs between [0.25-0.75], [1-1.25], [1.5-1.75], [2-2.5], [2.75-6.5], and [6.75-9.5] hr after triggering in the control simulation. The $x$ axis is on logarithmic scale. (b-d) Composite time series of (b) mean rain core radius $R$, (c) standard deviation of rain core radii, $\sigma_{R}$, and (d) number of rainfall events $N$ obtained in the (black) control simulation, and the (blue) weakly and (red) strongly forced simulations. The shaded areas indicate the cycle-to-cycle fluctuations relative to the ensemble mean value (standard deviation) and the time axis is shifted such that time equals 0 corresponds to the time of triggering in all three simulations.

forced simulation) after triggering, followed by an oscillatory stage when the mean rain core radius oscillates slowly around its equilibrium value.

During the growing stage, there are clear dependencies on forcing strength. The mean radius and standard deviation increase with the strength of forcing, while the number of rainfall events is relatively insensitive. The number of rainfall events increases rapidly and reaches its peak at $1.25 \mathrm{hr}$ (in the control and strongly forced simulations) or $1.5 \mathrm{hr}$ (in the weakly forced simulation) after triggering, before decreasing rapidly to much smaller values at the end of the growing stage. The rapid reduction in the number of rainfall events alongside a gradual growth of their average sizes (between $t_{0}=1.5$ and $2.5 \mathrm{hr}$ ) could suggest that smaller rainfall events disappear or else merge together to form larger events.

During the oscillatory stage, there is no clear separation in the evolution of the mean radii and standard deviation of rain core radii. The number of rainfall events continues to decrease and reaches the value of zero when precipitation stops. The control and strongly forced simulations generate very similar number of rainfall events from Hour 3.25 after triggering, while the weakly forced simulations generates fewer rainfall events from about Hour 6 after triggering. In all three simulations the mean rain core size does not vary 

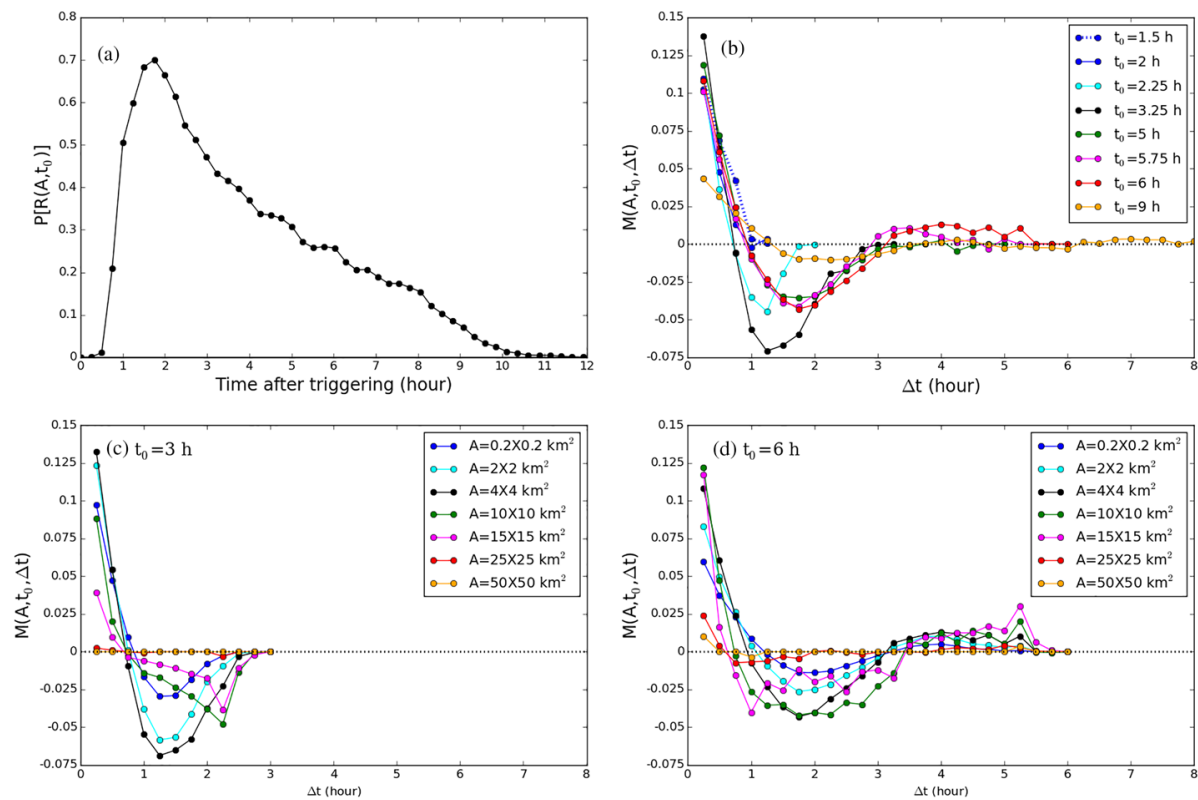

Figure 5. (a) Probability of finding rain $\left(P\left[R\left(A, t_{0}\right)\right]\right)$ for $A=4 \times 4 \mathrm{~km}^{2}$. The time axis is shifted such that time equals 0 corresponds to the time of triggering. (b) Memory function $\left(\mathbf{M}\left(A, t_{0}, \Delta t\right)\right)$ for $A=4 \times 4 \mathrm{~km}^{2}$ and $t_{0}=1.5,2,2.25,3.25$, 5,6 , and $9 \mathrm{hr}$ after triggering. The memory functions for different areas are shown for $t_{0}=$ (c) 3 and (d) $6 \mathrm{hr}$ after triggering. Results are shown for the control simulation.

substantially with time (compared to the number of rainfall events), away from triggering. This latter result suggests that regardless of the strength of forcing the evolution of convection produced by a time-varying surface forcing is mainly dominated by the variability in time on the number of rainfall events, with the variability in time on the rainfall characteristics (e.g., rain core size) being less important. It is consistent with the result of Davies et al. (2013), who found that changes in mass flux are dominated by changes in the number of clouds, rather than changes in the cloud size or changes in strength of surface forcing.

\subsubsection{Memory Within the Convective System}

We now investigate how current convection depends on its own history within a given area, $A$. For each instantaneous 2-D surface precipitation field, the $512 \times 512$ (grid-scale) data are averaged onto a $N_{A_{x}} \times N_{A_{y}}$ domain. Each area $A=N_{A_{x}} \Delta x \times N_{A_{y}} \Delta y$ on the coarse-grained scale is considered to have rain present if its mean precipitation is greater than $0.1 \mathrm{~mm} \mathrm{hr}^{-1}$ and we denote the probability of finding rain at time $t_{0}$ within some area $A$ as $P\left[R\left(A, t_{0}\right)\right]$. Figure 5a shows the probability of finding rain for $A=4 \times 4 \mathrm{~km}^{2}$ in the control simulation. Results are the ensemble mean over the last nine cycles and the time axis is shifted such that time equals 0 corresponds to the time of triggering. The probability of finding rain increases rapidly and reaches its maximum value at $1.75 \mathrm{hr}$ after triggering, before decreasing to zero when precipitation stops.

The persistence of rainfall events within area $A$ is measured in terms of the probability of finding rain at time $t_{0}$ and at an earlier time $t_{0}-\Delta t, P\left[R\left(A, t_{0}\right) \cap R\left(A, t_{0}-\Delta t\right)\right]$. The minimum persistence of zero is obtained if all the areas which were precipitating at time $t_{0}-\Delta t$ are not precipitating at time $t_{0}$. The maximum persistence is either $P\left[R\left(A, t_{0}-\Delta t\right)\right]$ if all areas which were precipitating at time $t_{0}-\Delta t$ are still precipitating at time $t_{0}$ or $P\left[R\left(A, t_{0}\right)\right]$ if all the areas which are precipitating at time $t_{0}$ were also precipitating at time $t_{0}-\Delta t$. We then evaluate the dependence of convection on its own history by comparing $P\left[R\left(A, t_{0}\right) \cap R\left(A, t_{0}-\Delta t\right)\right]$ to the probability of finding persistent rainfall by random chance (or the expected probability given no memory). That is $P^{2}\left[R\left(A, t_{0}, \Delta t\right)\right]=P\left[R\left(A, t_{0}\right)\right] \times P\left[R\left(A, t_{0}-\Delta t\right)\right]$.

Convection depends on its own history if $P\left[R\left(A, t_{0}\right) \cap R\left(A, t_{0}-\Delta t\right)\right]$ is significantly different from the expected probability given no memory. A memory function that defines the influence from convection at $t_{0}-\Delta t$ is defined as 


$$
\mathbf{M}\left(A, t_{0}, \Delta t\right)=P\left[R\left(A, t_{0}\right) \cap R\left(A, t_{0}-\Delta t\right)\right]-P^{2}\left[R\left(A, t_{0}, \Delta t\right)\right]
$$

Figure $5 \mathrm{~b}$ shows the evolution of the memory function during a course of a day. Results are shown for $A=4 \times 4 \mathrm{~km}^{2}$ and $t_{0}=1.5,2,2.25,3.25,5,5.75,6$, and $9 \mathrm{hr}$ after triggering. Note that the memory function is set to zero beyond time lags, which corresponds to times before triggering. A positive (negative) memory implies that convection at previous time $t_{0}-\Delta t$ acts to enhance (suppress) convective activities at time $t_{0}$. The minimum value of $\mathbf{M}$ represents the strongest suppressed state of convection and the transition from this strongest suppressed state to the state expected given no memory (the zero line in Figure 5) corresponds to the recovery time of convection. A somewhat similar memory function was also considered by Colin et al. (2019, section 5 of supplementary material), who focused on assessing the time for the domain mean precipitation to recover following a homogenization of spatial variations.

In the early stage of the diurnal cycle the memory function characterizes the persistence of the newly developing convection. Later in the day, the persistence of convection is maintained for about an hour. An indication of local suppression is obtained for convection produced from $t_{0}=2.25 \mathrm{hr}$, suggesting that earlier convection stabilized the local area and so produced a negative feedback on the subsequent development of convection within the local area. From $t_{0}=2.25 \mathrm{hr}$, the initial persistence of convection is followed by a suppression for a further $1 \mathrm{hr}$ (for convection produced at $t_{0}=2.25 \mathrm{hr}$ ) to $2 \mathrm{hr}$ (for convection produced from $t_{0}=3.25 \mathrm{hr}$ ) within the local areas where convection where previously enhanced. The time lag at which the strongest memory occurs is slightly delayed for longer $t_{0}$. It occurs at $\Delta t=1.25 \mathrm{hr}$ for convection produced at $t_{0}=2.25 \mathrm{hr}$ and at $\Delta t=1.75 \mathrm{hr}$ for convection produced from $t_{0}=5 \mathrm{hr}$. The memory function obtained between $t_{0}=5.75$ and $7.25 \mathrm{hr}$ (e.g., red curve in Figure $5 \mathrm{~b}$ ) shows a further enhancement of convection for time lags of $\Delta t=3-5 \mathrm{hr}$, suggesting that areas which were less likely to rain during the previous $2 \mathrm{hr}$ may become more favorable for developing convection.

We investigated the sensitivity to several of the control simulation settings (not shown). These memory functions are qualitatively reproduced using shorter simulations with finer horizontal resolution (e.g., $100 \mathrm{~m}$ ) and using simulations on a bigger domain with coarser horizontal resolution (e.g., $256 \times 256 \mathrm{~km}$ with $500 \mathrm{~m}$ grid spacing). They are also well reproduced using simulations with different radiative cooling profiles (e.g., $-2 \mathrm{~K}$ day $^{-1}$ without additional cooling near the surface) or different initial thermodynamic profiles (e.g., profiles obtained at the end of each forcing cycle). We also tested the sensitivity to a smaller Bowen ratio by decreasing the peak in surface sensible heat flux while increasing that in latent heat flux. The convection exhibits similar behavior as in the control simulation, and the memory functions are also very similar.

We now investigate the sensitivity of the memory function to the size of the area. The memory function for $A=4 \times 4 \mathrm{~km}^{2}$ is compared to those obtained for $A=0.2 \times 0.2$ (grid-scale), $2 \times 2,10 \times 10,15 \times 15,25 \times 25$, and $50 \times 50 \mathrm{~km}^{2}$. Results are shown in Figures $5 \mathrm{c}$ and $5 \mathrm{~d}$ for $t_{0}=3$ and $6 \mathrm{hr}$ after triggering. During the course of the day the shapes of the memory functions obtained for areas smaller than $10 \times 10 \mathrm{~km}^{2}$ are qualitatively similar and the strongest memory is obtained for areas between $4 \times 4$ and $10 \times 10 \mathrm{~km}^{2}$ (Figures $5 \mathrm{c}$ and $5 \mathrm{~d}$ ). The memory function shows a somewhat different behavior for areas of $10 \times 10 \mathrm{~km}^{2}$ and larger. For instance, for a $15 \times 15 \mathrm{~km}^{2}$ area convection occurring at $t_{0}=3 \mathrm{hr}$ (Figure $5 \mathrm{c}$ ) starts to recover from a time lag of $\Delta t=2.5 \mathrm{hr}$ (time lag when the memory function starts to increase from its minimum value toward the zero line) compared to $\Delta t=1.5 \mathrm{hr}$ for $A=4 \times 4 \mathrm{~km}^{2}$. However, the impact of previous convection is reduced substantially for an area of $25 \times 25 \mathrm{~km}^{2}$ and convective memory is negligible for areas exceeding $25 \times 25 \mathrm{~km}^{2}$ (e.g., $A=50 \times 50 \mathrm{~km}^{2}$ ). We should note that the strongest memory occurs on spatial scales of very large rainfall events (Figure 4a) while the change of behavior of the memory function occurs on a spatial scale that is roughly the typical spacing of rain cores. For instance, for $N=100$ the typical spacing is $\sqrt{(512 \times 0.2)^{2} / 100} \approx 10 \mathrm{~km}$.

Finally, we investigate the sensitivity to the strength of forcing. Figure 6a compares the probability of finding rain for $A=4 \times 4 \mathrm{~km}^{2}$. The time axis is shifted such that time equals 0 corresponds to the time of triggering in all three simulations. The maximum value is reached at $1.75 \mathrm{hr}$ after triggering in all three simulations. Note that the probability of finding rain is broadly equivalent to the rain area fraction and thus the differences in the probability of finding rain between the simulations can be understood in terms of the 

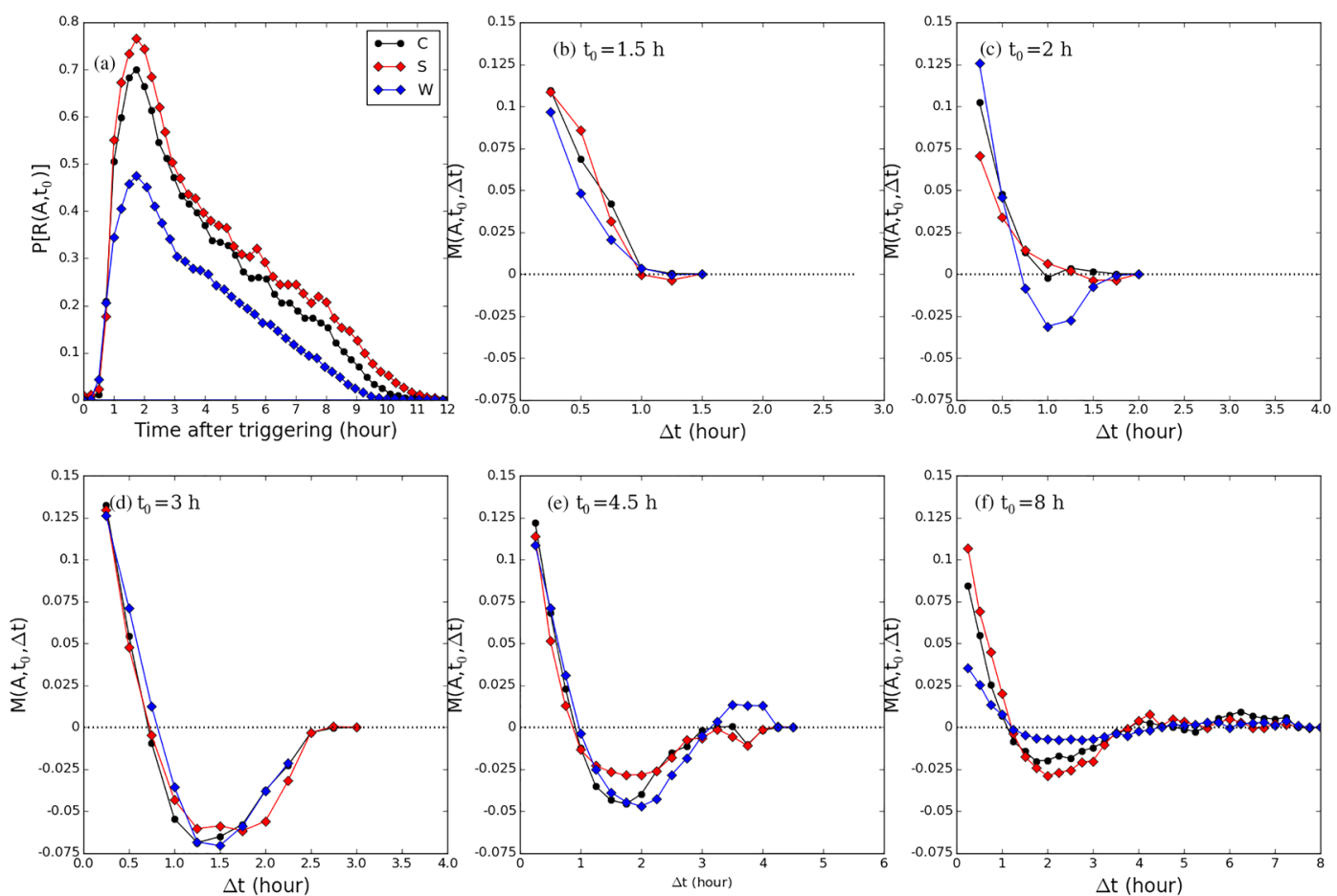

Figure 6. (a) Probability of finding rain $\left(P\left[R\left(A, t_{0}\right)\right]\right)$ for $A=4 \times 4 \mathrm{~km}^{2}$. The time axis is shifted such that time equals 0 corresponds to the time of triggering in all three simulations. Memory function $\left(\mathbf{M}\left(A, t_{0}, \Delta t\right)\right)$ for $A=4 \times 4 \mathrm{~km}^{2}$ and $t_{0}=$ (b) 1.5 , (c) 2, (d) 3, (e) 4.5, and (f) $8 \mathrm{hr}$ after triggering. Results are the ensemble mean obtained in the (black) control simulation, and the (blue) weakly and (red) strongly forced simulations.

differences in the number of rainfall events and their sizes. The probability of finding rain in the weakly forced simulation is the smallest as this simulation generates smaller rain core sizes throughout the day and fewer rainfall events from Hour 6 after triggering (Figure 4). During the growing stage, the probability of finding rain in the strongly forced simulation is the greatest, suggesting that the contributions from slightly fewer and larger rainfall events exceed those from more numerous but smaller rainfall events (control simulation). During the oscillatory stage, the control and strongly forced simulations generate very similar numbers of rainfall events. However, the probability of finding rain in the strongly forced simulation remains greater because that simulation generates larger rain core sizes.

In all three simulations the strongest memory is obtained for areas between $4 \times 4$ and $10 \times 10 \mathrm{~km}^{2}$. Figures 6b-6f compare the memory functions for $A=4 \times 4 \mathrm{~km}^{2}$ and $t_{0}=1.5,2,3,4.5$, and $8 \mathrm{hr}$ after triggering. The fundamental behavior of convection in the control and strongly forced simulations are similar as both simulations have qualitatively similar evolution of the memory function. However, the memory function in the weakly forced simulation shows a few differences. For instance, the negative memory develops a little earlier in the weakly forced simulation (Figure 6c). In addition, the appearance of a secondary enhancement of precipitation occurs earlier in the diurnal cycle. It occurs at $t_{0}=4.5 \mathrm{hr}$ in the weakly forced simulation (Figure 6e) compared to $t_{0}=5.75 \mathrm{hr}$ in the control simulation (e.g., gray curve in Figure $5 \mathrm{~b}$ ) and the strongly forced simulation (not shown). On the other hand, the memory functions are quantitatively different and the impact of previous convection increases with the strength of surface forcing for convection produced from $t_{0}=7 \mathrm{hr}$ (e.g., $t_{0}=8 \mathrm{hr}$ in Figure 6f). Moreover, in all three simulations the convective memory is reduced significantly when areas greater than $25 \times 25 \mathrm{~km}^{2}$ are considered, and there is no convective memory for $A=50 \times 50 \mathrm{~km}^{2}$.

These memory functions illustrate the role of previous convection in modulating current convection and highlight the importance of the area of the region considered in modulating memory effects as well as the time since triggering $\left(t_{0}\right)$. The strength of forcing is a secondary factor. These results suggest that for disorganized convection there is no memory due to the mechanisms at play in these simulations for GCMs with grid spacings coarser than $50 \mathrm{~km}$. However, these memory functions are inconsistent with diagnostic 

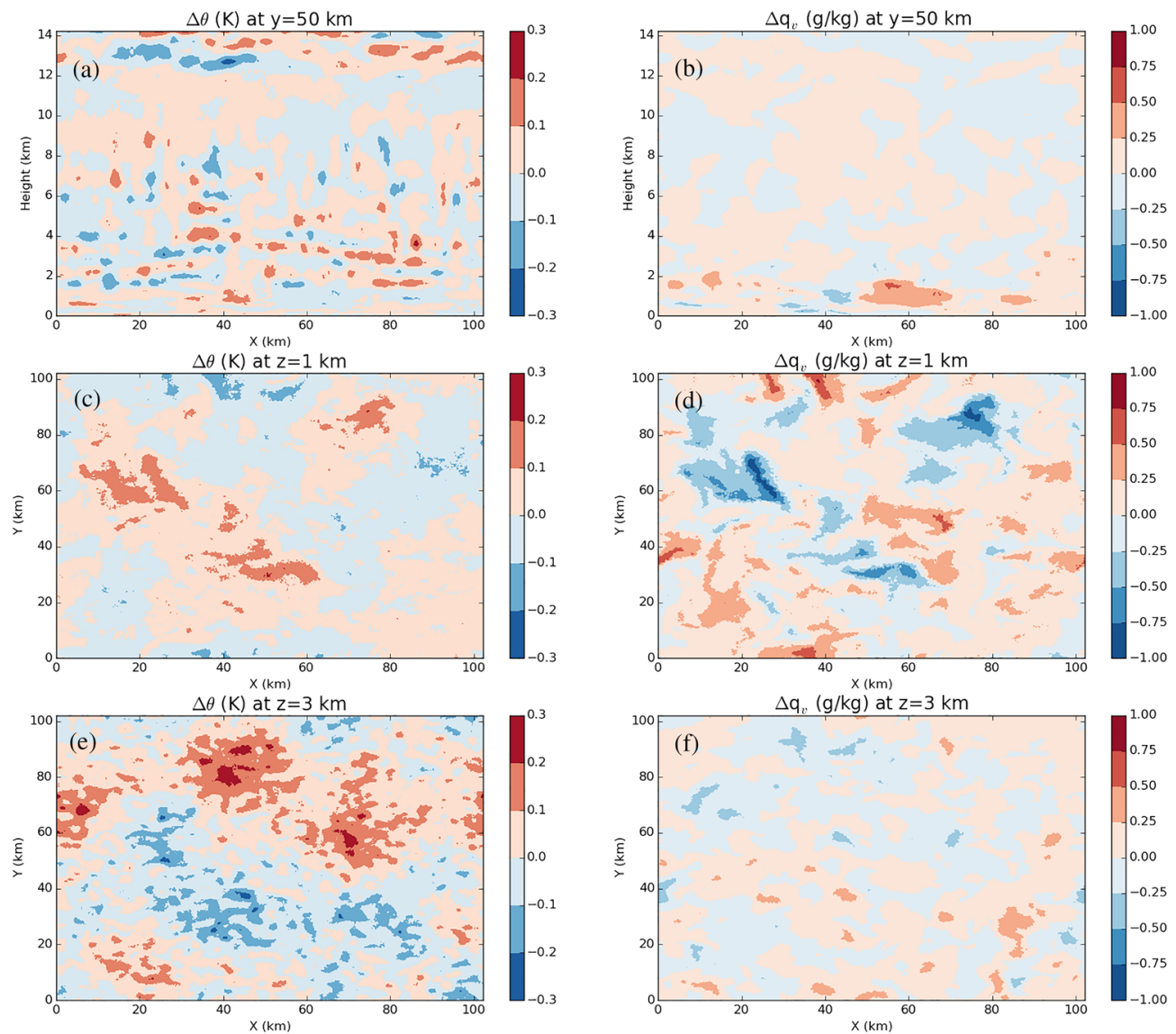

Figure 7. Snapshots of vertical slices at (a and b) $y=50 \mathrm{~km}$ and horizontal slices at heights of (c and d) 1 and (e and f) $3 \mathrm{~km}$ of (left-hand side) potential temperature and (right-hand side) water vapor anomalies with respect to the domain mean. Results are taken at $24 \mathrm{hr}$ of the second forcing cycle of the control simulation.

assumptions made in many current convective parameterization schemes as used in numerical weather prediction models with grid spacing finer than $10 \mathrm{~km}$.

\section{Convective Memory Attributed to Initial Thermodynamic Variability}

Each diurnal cycle experiences the same forcing but starts from a slightly different initial state due to spatial variability. Figure 7 shows snapshots of vertical slices at $y=50 \mathrm{~km}(\mathrm{a}, \mathrm{b})$ and horizontal slices at heights of 1 (c, d) and $3 \mathrm{~km}$ (e, f) of potential temperature and water vapor anomalies with respect to the domain mean. These slices are taken at $24 \mathrm{hr}$ of the second forcing cycle of the control simulation, and they represent the fluctuations in the thermodynamic fields at the start of surface forcing on the third diurnal cycle. Similar magnitudes of the thermodynamic fluctuations are obtained at night on the other diurnal cycles of the control simulation.

Below $4 \mathrm{~km}$, a notable feature is the evidence of an anticorrelation between moisture and temperature. For instance, there are large patches of moist (dry) anomaly of up to $1.2 \mathrm{~g} / \mathrm{kg}$ on horizontal scales of around 40 $\mathrm{km}$ which are associated with a cold (warm) anomaly of up to $0.4 \mathrm{~K}$. Above $4 \mathrm{~km}$ moisture fluctuations are relatively small compared to those in the lowest $4 \mathrm{~km}$ at $24 \mathrm{hr}$. However, the potential temperature field shows more significant small-scale fluctuations which are presumably associated with gravity waves initiated at detrainment layers when convective cells were active, transporting heat away from the convective cells. As we will show later these thermodynamic fluctuations above $4 \mathrm{~km}$ do not influence the evolution of convection on the next diurnal cycle. 

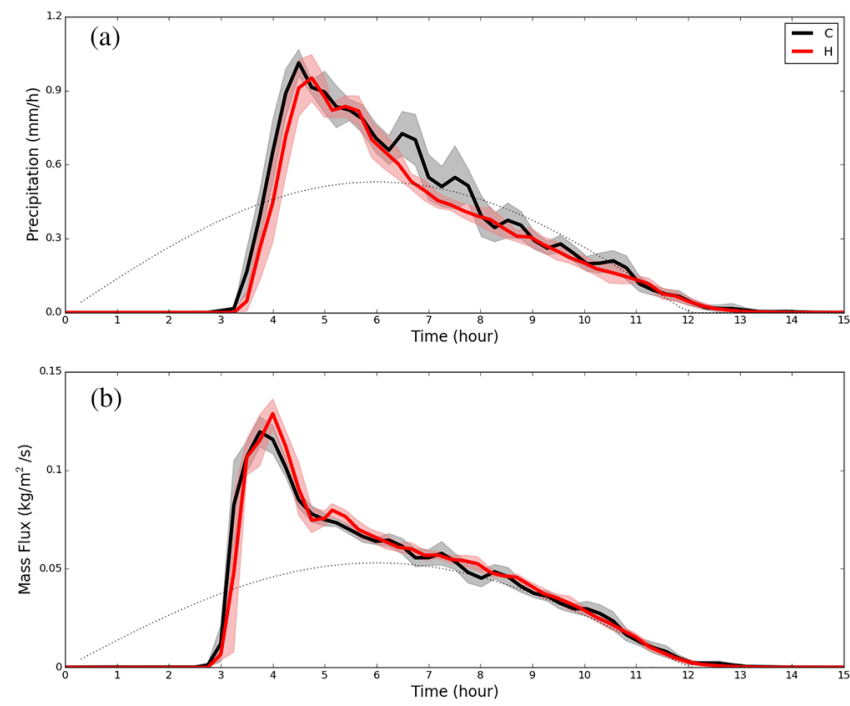

Figure 8. As in Figures $2 \mathrm{a}$ and $2 \mathrm{~b}$ but for the (black) control simulation and (red) the simulations following homogenization of $\theta$ and $q_{v}$ at all vertical levels. The cloud base mass flux are shown for "ACu."
The diurnal cycle $i$ is thus initialized with horizontally heterogeneous thermodynamic conditions generated internally via decaying deep convection from cycle $i-1$. In order to understand whether these thermodynamic fluctuations have an impact on the evolution of convection on the $i$ th cycle, we perform simulations in which horizontally homogeneous thermodynamic conditions (hereafter called "homogenization") are imposed (without changing the domain mean state). Homogenization is applied to a thermodynamic field by relaxing that field back to its horizontal mean.

Previous studies on convective memory have explored the relative importance of different prognostic variables and concluded that horizontal variations in potential temperature $(\theta)$ and water vapor mixing ratio $\left(q_{v}\right)$ are the main source of convective memory (e.g., Colin et al., 2019; Davies et al., 2013; Stirling \& Petch, 2004). We repeated the control simulation and similarly to Colin et al. (2019), applied homogenization to both $\theta$ and $q_{v}$ at all vertical levels between 15 and $24 \mathrm{hr}$ of the diurnal cycle $i-1$, before allowing them to continue evolving. Here, homogenization is applied with a relaxation time scale of $1 \mathrm{hr}$ and there is no thermodynamic variability left at the start of the diurnal cycle $i$. The cycle $i$ will henceforth be referred to as $H^{D a y^{i}}$ and will be compared against the control simulation on the $i$ th diurnal cycle $\left(C^{D a y^{i}}\right) \cdot C^{D a y^{i}}$ and $H^{D a y^{i}}$ start with the same domain mean thermodynamic profiles but in contrast to $C^{D a y^{i}}$, the evolution of convection in $H^{D a y^{i}}$ is not influenced by variability arising from the previous day.
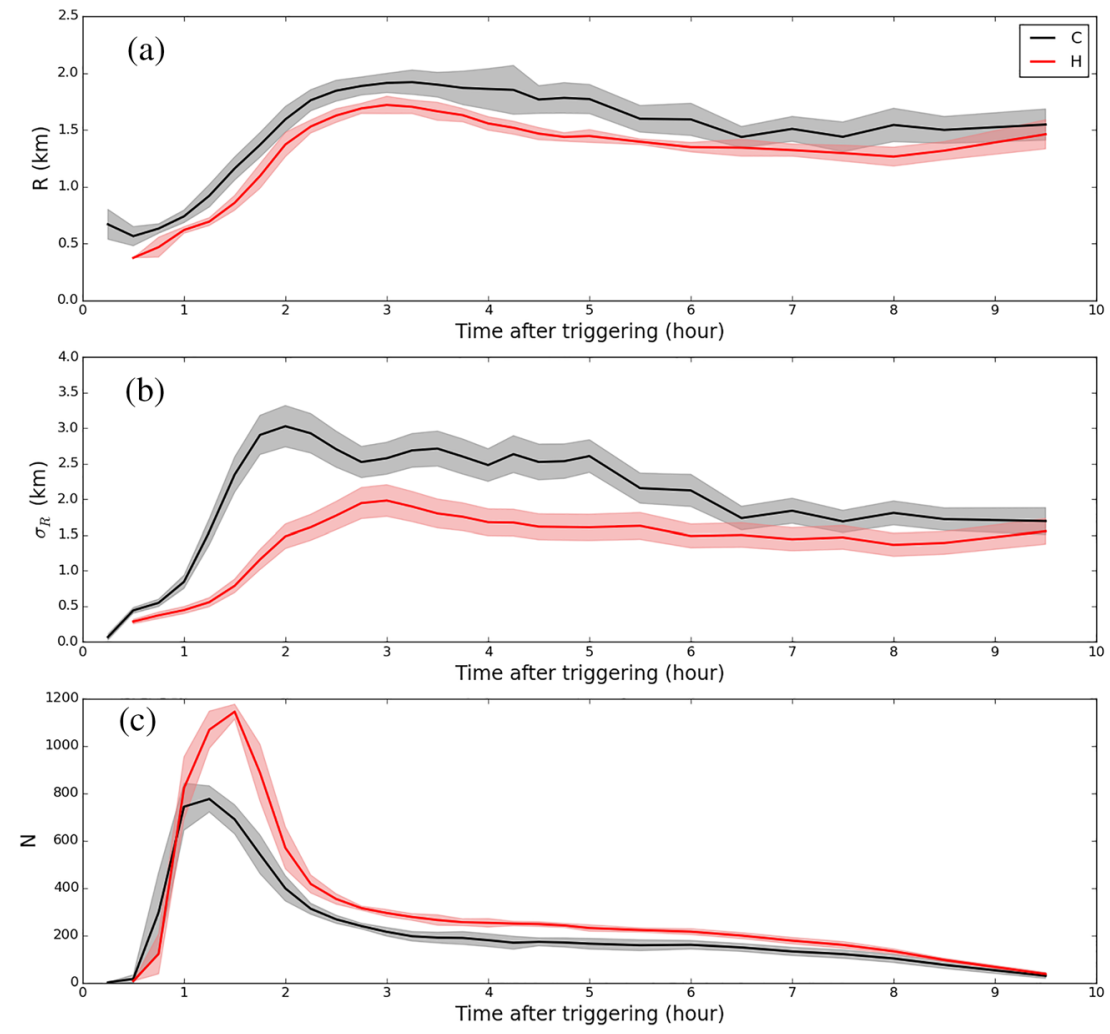

Figure 9. $(a-c)$ As in Figures $4 b-4 d$ but for the (black) control simulation and (red) the simulations following homogenization of $\theta$ and $q_{v}$ at all vertical levels. The time axis is shifted such that time equals 0 corresponds to the time of triggering. 

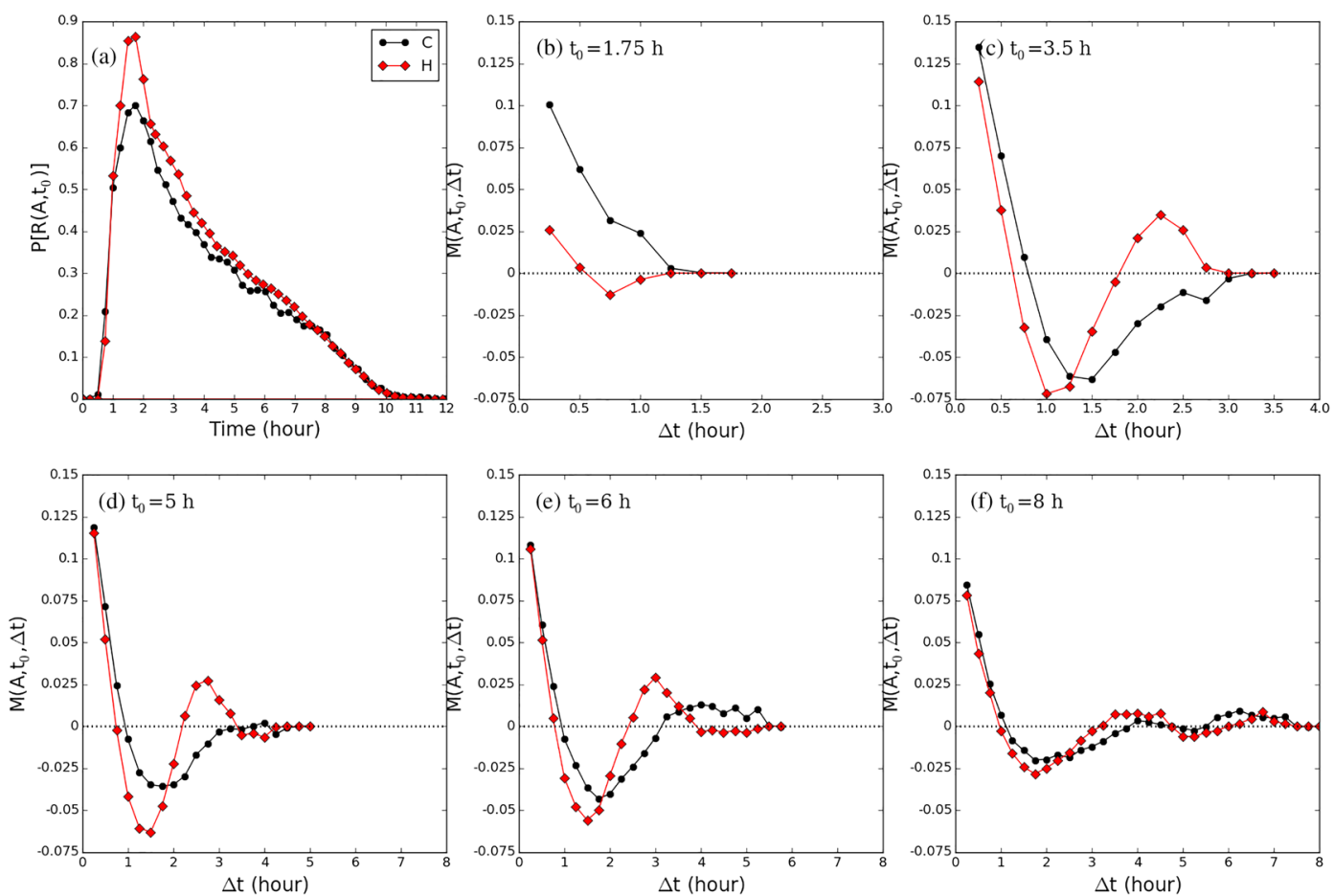

Figure 10. (a) Probability of finding rain $\left(P\left[R\left(A, t_{0}\right)\right]\right)$ for $A=4 \times 4 \mathrm{~km}^{2}$. The time axis is shifted such that time equals 0 corresponds to the time of triggering in both cases. Memory function $\left(\mathbf{M}\left(A, t_{0}, \Delta t\right)\right)$ for $A=4 \times 4 \mathrm{~km}^{2}$ and $t_{0}=(\mathrm{b}) 1.75$, (c) 3.5, (d) 5, (e) 6, and (f) $8 \mathrm{hr}$ after triggering. Results are the ensemble mean of the (black) control simulation, and the (red) simulations following homogenization of $\theta$ and $q_{v}$ at all vertical levels.

Homogenization is realized 9 times (for $i$ between 2 and 10) and for each of these nine realizations the start of the simulation on the $i$ th diurnal cycle is considered to be Time 0 and the ensemble mean results are obtained by averaging the results of the nine realizations. Figure 8 compares the composite time series of the surface precipitation and cloud base mass flux for the control simulation and the simulations following homogenization. The triggering of convection occurs at the same time. However, the start of precipitation and its development are a little delayed $(15 \mathrm{~min})$ by homogenization. In addition, the domain mean daily mean precipitation rate is reduced by about $10 \%$, now $0.18 \mathrm{~mm} \mathrm{day}^{-1}$ compared to $0.2 \mathrm{~mm} \mathrm{day}^{-1}$ in the control simulation. These results are in contrast with those obtained by Stirling and Petch (2004) who found that the onset of precipitation occurred several hours earlier and that the total rainfall amount is increased by up to $70 \%$ when diurnal cycle simulations were initialized with thermodynamic fluctuations generated from a day of deep convection. However, in contrast to this study, the study of Stirling and Petch (2004) was conducted in 2-D domain, which may enhance the significance of the fluctuations on initiation. On the other hand, this study analyses the impact from thermodynamic fluctuations that have decayed for $12 \mathrm{hr}$ following a day of deep convection and this leads to fluctuation amplitudes at least 6 times smaller than those of Stirling and Petch (2004) (compare our Figure 7 with their Figure 2).

However, there are clear differences in the evolution of the rainfall population (Figure 9). Following homogenization, the rain core size distribution is narrower and more numerous and smaller rainfall events occur throughout the course of the day. The number of rainfall events reaches its peak at $1.5 \mathrm{hr}$ after triggering and the peak is increased by about 350 (about 50\% increase with respect to the control simulation). Recalling also that homogenization reduces the rainfall amount by about $10 \%$ and that the domain mean cloud base mass flux values are very similar, convective activity associated with the individual rainfall event generated in the simulations following homogenization is clearly less intense (in mass flux and rainfall amount) than those generated in the control simulation.

Following homogenization, the more numerous rainfall events result in larger chances of finding rainfall event during the first $8 \mathrm{hr}$ after triggering (Figure 10a). The strongest memory is also obtained for areas 
between $4 \times 4$ and $10 \times 10 \mathrm{~km}^{2}$. Figures 10b-10f compare the memory functions for $A=4 \times 4 \mathrm{~km}^{2}$ and $t_{0}=1.75,3.5,5,6$, and $8 \mathrm{hr}$ after triggering. The variability in the initial thermodynamic fields appears to be important in controlling the shape of the memory function during the course of the day. The rainfall events generated following homogenization are less intense, and somewhat less persistent and the negative memory and secondary enhancement develop earlier (Figure 10c). On the other hand, the local atmosphere also recovers more rapidly: up to $1.5 \mathrm{hr}$ earlier for convection produced between $t_{0}=2.5$ and $6.5 \mathrm{hr}$ (e.g., Figure 10c). The character of these differences in the memory functions between the control simulation and the simulations following homogenization are consistent across the various areas considered.

We further test where the important thermodynamic fluctuations occur by performing additional simulations in which homogenization is restricted to the lower troposphere (surface to $4 \mathrm{~km}$ ) or to the middle and upper troposphere $(4-20 \mathrm{~km})$. The effects of homogenization are almost zero when applied above 4 $\mathrm{km}$. However, the simulations following homogenization below $4 \mathrm{~km}$ and following homogenization at all vertical levels behave very similarly. These results are consistent with those of Stirling and Petch (2004) and Colin et al. (2019), who demonstrated that thermodynamic fluctuations at low levels have the greatest impact on the development of convection.

\section{Conclusions}

A series of idealized high-resolution three-dimensional simulations of the diurnal cycle of deep convection over land have been performed using the MONC. The simulations have features expected from diurnal cycle of tropical convection. In this study convection is found to be disorganized. A memory function is defined to evaluate the effects of previous convection in modifying current convection. It is the difference between the probability of finding rain at time $t_{0}$ and at an earlier time $t_{0}-\Delta t$ and the expected probability given no memory. The shapes of the memory function are similar at gray-zone scales, but there is a change in the shape at spatial scales of $10 \mathrm{~km}$ and larger, and convective memory is reduced substantially when spatial scales larger than $25 \mathrm{~km}$ are considered. The memory is found to be strongest at gray-zone scales. In the early stage of the diurnal cycle the memory function has one phase which characterizes the persistence of the newly developing convective system. Later in the day, the first phase which represents the persistence of convection is maintained for about an hour. There is a second phase which represents the suppression of convection in regions which were raining 1 to $3 \mathrm{hr}$ previously, and subsequently a third phase which represents a secondary enhancement of precipitation but this is likely related to the previous suppression rather than the occurrence of rainfall 3 to $6 \mathrm{hr}$ ago. Each phase of the memory function roughly keeps the same duration regardless of surface forcing. The second and third phases are found to develop earlier for the weaker forcing, but the memory function shows less sensitivity to the stronger forcing. Note that for stronger forcing clouds are found to be more intense in rainfall amount and mass flux (or vertical velocity) and so they are expected to be more intense in terms of the strength of the associated cold pool activity. Hence, if the strength of the cold pool were driving the memory we would expect the memory to depend on the intensity of those clouds and so, to also depend on the strength of the forcing. The lack of dependence of convective memory to the strength of forcing therefore challenges assumptions made in cold pool models for memory, where the forcing for cold pool activity depends on the strength of large-scale convective activity.

Sensitivity studies were carried out to investigate the impact of thermodynamic variability generated via feedback processes from previous daytime convection on the development of convection on the next day. In contrast to the study of Stirling and Petch (2004), which showed that the onset of precipitation can change by several hours and convection intensity can be increased by up to $70 \%$ when simulations are initialized with convectively generated thermodynamic fluctuations, our study revealed little impact on the timing of convection and convection intensity is reduced by only $10 \%$ when thermodynamic fluctuations are removed. The difference in the results is attributed to the fact that the amplitudes of thermodynamic fluctuations in our study are smaller compared to those in the study of Stirling and Petch (2004) due to their decay during the night. However, it was shown that thermodynamic fluctuations do have a significant impact on the nature of the rainfall events during the course of the day. Rainfall events become numerous but less intense, with relatively smaller sizes when feedback of previous daytime convection is excluded in the simulation of the next day. As a result, the memory function exhibits more rapid decay and recovery. Additional sensitivity studies revealed that thermodynamic fluctuations in the middle and upper tropospheres do not affect 
the evolution of convection and confirmed the results of the studies of (Colin et al., 2019; Stirling \& Petch, 2004) which demonstrated that convective memory attributed to thermodynamic fluctuations mostly resides in the lower troposphere.

This study highlights the impacts of spatial thermodynamic variability on the subsequent development of convection and highlights the importance of the area of the grid box, the time since triggering, and the strength of forcing in modulating memory effects at gray-zone scales. The first phase of the memory function, with enhanced precipitation where it was already precipitating in the past, is in principle already represented by some memory mechanisms included in some convective parameterization schemes (e.g., Willett \& Whitall, 2017). However, the second phase, with suppressed precipitation where it was previously enhanced and the third phase, with a secondary enhancement of precipitation where it was previously suppressed are not yet directly represented in convective parameterization schemes. Future studies are planned to assess the ability of current convective parameterizations in capturing such effects via their feedbacks onto the resolved state. This will be done by comparing the memory properties in CRM simulations, including their dependencies on spatial scale and forcing strengths, against equivalent simulations with GCMs.

These simulations represent diurnal cycle of scattered convection under very idealized forcing conditions and for more realistic simulations the memory properties of convection may be modified for mesoscale organized convection or by the presence of an interactive land-surface; vertical wind shear; or cloud-radiative interactions. However, the simulations provide a benchmark against which to compare more complex simulations of the diurnal cycle and future studies are also planned to investigate the impact of prescribed heterogeneous surface conditions on the diurnal cycle of deep convection.

\section{Data Availability Statement}

The model data from the experiments performed in this study and the scripts used to analyze those data are available in a Zenodo repository (https://zenodo.org/record/3909834\#.XvZR8HduKUk).

\section{Acknowledgments}

C. L. D., R. S. P., and S. J. W. are supported by the RevCon project NE/N013743/1, funded by Natural Environment Research Council (NERC) under the joint NERC/Met Office ParaCon program. N. J. H. is supported by the IMPALA project NE/M017222/1, funded by NERC and DFID as part of the Future Climate for Africa (FCFA) program. The simulations have been conducted on Monsoon, a collaborative High Performance Computing facility funded by the Met Office and NERC. We acknowledge use of the NEXCS system, a collaborative facility supplied under the Joint Weather and Climate Research Programme, a strategic partnership between the Met Office and NERC.

\section{References}

Arakawa, A. (2004). The cumulus parameterization problem: Past, present, and future. Journal of Climate, 17, $2493-2525$.

Arakawa, A., \& Schubert, W. H. (1974). Interaction of a cumulus cloud ensemble with the large-scale environment, Part I. Journal of the Atmospheric Sciences, 31, 674-701.

Bechtold, P., Chaboureau, J. P., Beljaars, A., Betts, A. K., Köhler, M., Miller, M., \& Redelsperger, J. L. (2004). The simulation of the diurnal cycle of convective precipitation over land in a global model. Quarterly Journal of the Royal Meteorological Society, 130, $3119-3137$.

Bechtold, P., Semane, N., Lopez, P., Chaboureau, J. P., Beljaars, A., \& Bormann, N. (2014). Representing equilibrium and nonequilibrium convection in large-scale models. Journal of the Atmospheric Sciences, 71, 734-753.

Betts, A. K., \& Jakob, C. (2002). Evaluation of the diurnal cycle of precipitation, surface thermodynamics, and surface fluxes in the ECMWF model using LBA data. Journal of Geophysical Research, 107, LBA 12-1-LBA 12-8.

Bluestein, H. B., \& Parker, S. S. (1993). Modes of isolated, severe convective storm formation along the dryline. Monthly Weather Review, $121,1354-1372$.

Brown, A. R. (1999). The sensitivity of large-eddy simulations of shallow cumulus convection to resolution and subgrid model. Quarterly Journal of the Royal Meteorological Society, 125, 469-482.

Brown, A. R., Cederwall, R. T., Chlond, A., Duynkerke, P. G., Golaz, J. C., Khairoutdinov, M., et al. (2002). Large-eddy simulation of the diurnal cycle of shallow cumulus convection over land. Quarterly Journal of the Royal Meteorological Society, 128, $1075-1093$.

Brown, N., Weiland, M., Hill, A., Shipway, B., Maynard, C., Allen, T., \& Rezny, M. (2015). A highly scalable Met Office NERC Cloud model. In Proceedings of the 3rd International Conference on Exascale Applications and Software (pp. 132-137).

Chen, D., \& Bougeault, P. (1992). A simple prognostic closure assumption to deep convective parameterization: I. Journal of Meteorological Research, 7, 1-18.

Clark, P. D., Choularton, T. W., Brown, P. R. A., Field, P. R., Illingworth, A. J., \& Hogan, R. J. (2005). Numerical modelling of mixed-phase frontal clouds observed during the CWVC project. Quarterly Journal of the Royal Meteorological Society, 131, 1677-1693.

Colin, M., Sherwood, S., Geoffroy, O., Bony, S., \& Fuchs, D. (2019). Identifying the sources of convective memory in cloud-resolving simulations. Journal of the Atmospheric Sciences, 76, 947-962.

Connolly, P. J., Choularton, T. W., Gallagher, M. W., Bower, K. N., Flynn, M. J., \& Whiteway, J. A. (2006). Cloud-resolving simulations of intense tropical Hector thunderstorms: Implications for aerosol-cloud interactions. Quarterly Journal of the Royal Meteorological Society, 132, 3079-3106

Connolly, P. J., Vaughan, G., Cook, P., Allen, G., Coe, H., Choularton, T. W., et al. (2013). Modelling the effects of gravity waves on stratocumulus clouds observed during VOCALS-UK. Atmospheric Chemistry and Physics, 13, 7133-7152.

Davies, L., Plant, R. S., \& Derbyshire, S. H. (2009). A simple model of convection with memory. Journal of Geophysical Research, 114, D17202. https://doi.org/10.1029/2008JD011653

Davies, L., Plant, R. S., \& Derbyshire, S. H. (2013). Departures from convective equilibrium with a rapidly varying surface forcing. Quarterly Journal of the Royal Meteorological Society, 139, 1731-1746.

Dearden, C., Hill, A., Coe, H., \& Choularton, T. (2018). The role of droplet sedimentation in the evolution of low-level clouds over southern West Africa. Atmospheric Chemistry and Physics, 18, 14,253-14,269.

Dudhia, J. M., Moncrieff, W., \& So, D. W. K. (1987). Quarterly Journal of the Royal Meteorological Society, 113, $121-146$. 
Grabowski, W. W. (2001). Coupling cloud processes with the large-scale dynamics using the cloud-resolving convection parameterization (CRCP). Journal of the Atmospheric Sciences, 58, 978-997.

Grandpeix, J. Y., \& Lafore, J. P. (2010). A density current parameterization coupled with Emanuel's convection scheme. Part I: The models. Journal of the Atmospheric Sciences, 67, 881-897.

Gray, M. E. B., Petch, J., Derbyshire, S. H., Brown, A. R., Lock, A. P., Swann, H. A., \& Brown, P. R. A. (2001). Version 2.3 of the Met Office large eddy model: Part II, Scientific documentation. Met Office (APR) Turbulence and Diffusion Rep, 276.

Grosvenor, D. P., Field, P. R., Hill, A. A., \& Shipway, B. J. (2017). The relative importance of macrophysical and cloud albedo changes for aerosol-induced radiative effects in closed-cell stratocumulus: Insight from the modelling of a case study. Atmospheric Chemistry and Physics, 17, 5155-5183.

Guichard, F., Petch, J. C., Redelsperger, J. L., Bechtold, P., Chaboureau, J. P., Cheinet, S., et al. (2004). Modelling the diurnal cycle of deep precipitating convection over land with cloud-resolving models and single-column models. Quarterly Journal of the Royal Meteorological Society, 130, 3139-3172.

Hohenegger, C., \& Stevens, B. (2013). Controls on and impacts of the diurnal cycle of deep convective precipitation. Journal of Advances in Modeling Earth Systems, 5, 801-815. https://doi.org/10.1002/2012MS000216

Khairoutdinov, M., \& Kogan, Y. (2000). A new cloud physics parameterization in a large-eddy simulation model of marine stratocumulus. Monthly Weather Review, 128, 229-243.

Khairoutdinov, M. F., \& Randall, D. A. (2001). A cloud resolving model as a cloud parameterization in the NCAR Community Climate System Model: Preliminary results. Geophysical Research Letters, 28, 3617-3620.

Khairoutdinov, M., Randall, D., \& DeMott, C. (2005). Simulations of the atmospheric general circulation using a cloud-resolving model as a superparameterization of physical processes. Journal of the Atmospheric Sciences, 62, 2136-2154.

Lee, M., Schubert, S. D., Suarez, M. J., Schemm, J. K., Pan, H. L., Han, J., \& Yoo, S. H. (2008). Role of convection triggers in the simulation of the diurnal cycle of precipitation over the United States Great Plains in a general circulation model. Journal of Geophysical Research, 113, D02111. https://doi.org/10.1029/2007JD008984

Lin, X., Randall, D. A., \& Fowler, L. D. (2000). Diurnal variability of the hydrologic cycle and radiative fluxes: Comparisons between observations and a GCM. Journal of Climate, 13, 4159-4179.

Mapes, B., \& Houze, R. A. (1992). An integrated view of the 1987 Australian monsoon and its mesoscale convective systems. I: Horizontal structure. Quarterly Journal of the Royal Meteorological Society, 118, 927-963.

Marsham, J. H., Dobbie, S., \& Hogan, R. J. (2006). Evaluation of a large-eddy model simulation of a mixed-phase altocumulus cloud using microwave radiometer, lidar and Doppler radar data. Quarterly Journal of the Royal Meteorological Society, 132, $1693-1715$.

Miltenberger, A. K., Field, P. R., Hill, A. A., Rosenberg, P., Shipway, B. J., Wilkinson, J. M., et al. (2018). Aerosol-cloud interactions in mixed-phase convective clouds-Part 1: Aerosol perturbations. Atmospheric Chemistry and Physics, 18, 3119-3145.

Park, S. (2014). A unified convection scheme (UNICON). Part I: Formulation. Journal of the Atmospheric Sciences, 71, $3902-3930$.

Park, S., Shin, J., Kim, S., Oh, E., \& Kim, Y. (2019). Global climate simulated by the Seoul National University Atmosphere Model Version 0 with a Unified Convection Scheme (SAM0-UNICON). Journal of Climate, 32, 2917-2949.

Petch, J. C., \& Gray, M. E. B. (2001). Sensitivity studies using a cloud-resolving model simulation of the tropical west Pacific. Quarterly Journal of the Royal Meteorological Society, 127, 2287-2306.

Randall, D. A., \& Pan, D. M. (1993). Implementation of the Arakawa-Schubert cumulus parameterization with a prognostic closure. In K. A. Emanuel, \& D. J. Raymond (Eds.), The representation of cumulus convection in numerical models (pp. 137-144). Boston, MA: American Meteorological Society.

Redelsperger, J. L., Parsons, D. B., \& Guichard, F. F. (2002). Recovery processes and factors limiting cloud-top height following the arrival of a dry intrusion observed during TOGA COARE. Journal of the Atmospheric Sciences, 59, 2438-2457.

Rio, C., Del Genio, A. D., \& Hourdin, F. (2019). Ongoing breakthroughs in convective parameterization. Journal of the Atmospheric Sciences, 5, 95-111.

Rio, C., Grandpeix, J. Y., Hourdin, F., Guichard, F., Couvreux, F., Lafore, J. P., et al. (2013). Control of deep convection by sub-cloud lifting processes: The ALP closure in the LMDZ5B general circulation model. Climate dynamics, 40, 2271-2292.

Shutts, G. J., \& Gray, M. E. B. (1994). A numerical modelling study of the geostrophic adjustment process following deep convection. Quarterly Journal of the Royal Meteorological Society, 120, 1145-1178.

Stevens, R. G., Loewe, K., Dearden, C., Dimitrelos, A., Possner, A., Eirund, G. K., et al. (2018). A model intercomparison of CCN-limited tenuous clouds in the high Arctic. Atmospheric Chemistry and Physics, 18, 11,041-11,071.

Stirling, A. J., \& Petch, J. C. (2004). The impacts of spatial variability on the development of convection. Quarterly Journal of the Royal Meteorological Society, 130, 3189-3206.

Stratton, R. A., \& Stirling, A. J. (2012). Improving the diurnal cycle of convection in GCMs. Quarterly Journal of the Royal Meteorological Society, 138, 1121-1134.

Tompkins, A. (2001). Organization of tropical convection in low vertical wind shears: The role of water vapor. Journal of the Atmospheric Sciences, 58, 529-545.

Weckwerth, T. M., Wilson, J. W., \& Wakimoto, R. M. (1996). Thermodynamic variability within the convective boundary layer due to horizontal convective rolls. Monthly Weather Review, 124, 769-784.

Willett, M. R., \& Whitall, M. A. (2017). A simple prognostic based convective entrainment rate for the unified model: Description and tests: Met Office. https://www.metoffice.gov.uk/binaries/content/assets/mohippo/pdf/library/frtr_617_2017p.pdf

Xie, S., Xu, K. M., Cederwall, R. T., Bechtold, P., Del Genio, A. G., Klein, S. A., et al. (2002). Intercomparison and evaluation of cumulus parametrizations under summertime midlatitude continental conditions. Quarterly Journal of the Royal Meteorological Society, 128, $1095-1135$.

Xu, K. M., Cederwall, R. T., Donner, L. J., Grabowski, W. W., Guichard, F., Johnson, D. E., et al. (2002). An intercomparison of cloud-resolving models with the atmospheric radiation measurement summer 1997 intensive observation period data. Quarterly Journal of the Royal Meteorological Society, 128, 593-624.

Yang, G. Y., \& Slingo, J. (2001). The diurnal cycle in the tropics. Monthly Weather Review, 129, 784-801.

Yano, J.-I., \& Plant, R. S. (2012). Convective quasi-equilibrium. Reviews of Geophysics, 50, RG4004. https://doi.org/10.1029/2011RG000378

Yano, J.-I., \& Plant, R. S. (2012). Finite departure from convective quasi-equilibrium: Periodic cycle and discharge-recharge mechanism. Quarterly Journal of the Royal Meteorological Society, 138, 626-637.

Young, G., Connolly, P. J., Jones, H. M., \& Choularton, T. W. (2017). Microphysical sensitivity of coupled springtime Arctic stratocumulus to modelled primary ice over the ice pack, marginal ice, and ocean. Atmospheric Chemistry and Physics, 17, 4209-4227. 